\title{
Factors influencing student usage of an online learning community: the case of a rural South African university
}

Willie Tafadzwa Chinyamurindi, Bright Mahembe, Tendai Chimucheka and Ellen Rungani

\begin{abstract}
:
Technology adoption within higher education is becoming popular. This has often resulted in hubs of learning referred to as an online learning community. The success of such platforms is dependent on full system utilisation. The study draws on a quantitative empirical investigation into the factors that influence the adoption of an online learning community amongst 252 first year students at a rural university in South Africa. The results of the study show that a positive relationship exists between online course design and student ratings of perceived usefulness and perceived interaction (PI) concerning the utilisation and usage of an online learning community. Furthermore, the online learning community's interface design was found to be positively related to ratings of perceived ease of use but not with PI. Based on these findings, interventions are proposed, which have ramifications in working within online learning communities to benefit both the student and the lecturer.
\end{abstract}

\section{Introduction}

The use of information and communication technologies (ICTs) has become popular in modern society (Yuan, Raubal and Liu, 2012), especially within higher education (Mohammadi, 2015). Within higher education, there is growing popularity in the use of online learning communities (Liu et al., 2010). An online learning community is a platform that allows for the use of technology to support and deliver learning amongst a group of people bound by the same identity features, values, beliefs, interests and goals (Hramiak, 2010; Ramage, 2010). Furthermore, within an online learning community, there is some sense of consensus amongst all members in learning needs being satisfied by pursuing a common learning goal (Rovai, 2002). Given this, a need exists to consider the needs and factors that influence how an online learning community functions especially when designing online learning courses (Dede, 1996).

This research focuses on understanding factors that influence student utilisation of an online learning community at a rural university in the Eastern Cape province of South Africa. The factors under investigation include (a) online course design (OCD), (b) user interface design (UID), (c) previous online learning experience (POE), (d) perceived usefulness (PU), (e) perceived ease of use (PEU), (f) perceived interaction (PI) (all independent variables) and (g) intention to use an online learning community (as a dependent 
variable). The rationale for this is motivated by two factors. First, empirical evidence shows the success of an e-learning system to be dependent on its full utilisation (Chinyamurindi and Louw, 2010; Chinyamurindi and Shava, 2015; Ilechukwu, 2013). This research was interested in ascertaining full systems utilisation of an online learning community by investigating those factors that influence student usage. This has the potential to benefit not only the student but also the lecturer designing the content on such platforms as online learning communities.

Second, interest was on using a sample of first-year university students and to understand their experience of using technology. First-year students from previously disadvantaged backgrounds have been found to encounter difficulty in their academic work (Zulu, 2011). A number of reasons for this, as proposed by various authors (Czerniewicz and Brown, 2014; Zulu, 2005, 2007, 2008) include being underprepared from high school, coming from under-resourced schools with no facilities such as libraries, and having little or no access to ICTs in their communities and schools. This study seeks to identify the factors influencing an online learning community amongst a sample of first-year students in not only empowering the student but also effective systems utilisation to facilitate teaching and learning.

The rest of the paper follows a structure. First, the concept of the online learning community as a technology innovation in higher education is presented. Second, the theoretical lens from which this work hinges on is presented. This leads to the research hypotheses and aims of the study. Thereafter, the empirical research is contextualised to include a presentation of the background, research sample, research paradigm, data collection instrument, process and the analytical framework used in this work. Finally, the results and discussion conclude this paper.

$2 \quad$ Literature review

$2.1 \quad$ The use of online learning communities as part of innovation in teaching

Online learning communities are those that consist of a human component (learners and instructors) and of a system element (online courses and online learning systems) (Liu et al., 2010). Such a community is based on the interaction between the human component and also the system elements (Foreman, 1999).

Online learning communities may have potential advantages as innovative ICTs. First, such communities may address constraints of time and distance, allowing for greater control of how students learn (Sun and Zhang, 2006). Second, such communities can use a wide repertoire of features to appeal to the varying needs and styles of learning of community members. These may include the use of bulletin boards, chat rooms, private email, course content management, quizzes and peer assessment (Saadé and Bahli, 2005). Finally, such communities can create a unique learning experience considering the diversity of its members in using features such as sound, video and interactive media (McNeil, Robin 
and Miller, 2000). This can be beneficial for not only the student but also the lecturer. The technology acceptance model (TAM) is used as a theoretical lens.

\section{$2.2 \quad$ Technology acceptance model}

The TAM is based on the idea of the utilisation of technology (Venkatesh and Davis, 2000). This model consists of two beliefs: PU and perceived ease of application, which determine attitudes towards the adoption of a new technology. The attitude towards adoption depicts the prospective adopter's positive or negative orientation/behaviour towards adopting a new technology (Venkatesh and Davis, 2000). Usage could also be influenced by a user's perception of their ability to use computers or computer selfefficacy (Compeau and Higgins, 1995). Subsequently, all these elements of TAM can serve as predictors of human behaviour (Lee and Lehto, 2013), resulting in TAM being seen as a useful predictor in explaining human behaviour concerning technology acceptance (Agundo-Peregrina, Hernández-García and Pascual-Miguel, 2014; Chen, Li and Li, 2011; Saadé, Nebebe and Tan, 2007).

In this work, a model using online learning communities is tested (Liu et al., 2010) amongst a South African cohort within a rural university in the Eastern Cape. The justification for this is due to the design of an online course in an online learning community being deemed as an important determinant for learning effectiveness (Fink, 2003). This makes it crucial for lecturers to find and adopt best-practice strategies of teaching, especially when designing technology-based teaching interventions (Liu et al., 2010). The model tested considers three external variables of intention to use an online learning community (ITU): (a) OCD, (b) UID and (c) POE. The model also considers perception variables such as (a) PU, (b) PEU and (c) PI. The next section presents empirical work using all these variables.

\subsection{Online course design}

The type of content for learners determines the course design (Liu et al., 2010). Furthermore, OCD has been found to be the success or failure of teaching using technology and teaching online (McGiven, 1994). Previous research has found OCD to be affected by PU of technology, PEU and PI (Liu et al., 2010). Thus, it can be expected that

H1: Online Course Design will positively affect the Perceived Usefulness of an online learning program.

H2: Online Course Design will positively affect the Perceived Ease of Use of an online learning program.

H3: Online Course Design will positively affect the Perceived Interaction with an online learning community. 


\section{$2.4 \quad$ User interface design}

UID is deemed critical when designing online learning programs (Liu et al., 2010). Focus should be on an UID that empowers learners (McKnight, Dillon and Richardson, 1996) thus allowing for easy operation and reducing cognitive load (Martin-Michiellot and Mendelsohn, 2000). A number of factors determine UID. Leflore (2000) suggested the arrangement of information influences UID. Others suggest an UID should encourage and facilitate learning (Liu, Chen and Sun, 2006) while leading to more interaction between the learner and the system (Wang and Yang, 2005). Furthermore, UID within an online learning community has been found to be positively affected by PEU and PI (Liu et al., 2010).

H4: User-interface Design will positively affect the Perceived Ease of Use of an online learning community.

H5: User-interface Design will positively affect Perceived Interaction with an online learning community.

\subsection{Previous online learning experience}

A user's online experience has been found to affect usage of online learning systems (Reed and Geissler, 1995). The online learning experience has been found to be related to elements of the TAM such as PU, PEU and intention to use an online learning community (Liu et al., 2010). In essence, a satisfying online experience may lead to better performance in the future (Shih, Muroz and Sanchez, 2006). Given this,

H6: Previous Online Learning Experience will positively affect the Perceived Usefulness of an online learning program.

H7: Previous Online Learning Experience will positively affect the Perceived Ease of Use of an online learning program.

H8: Previous Online Learning Experience will positively affect the Intention to Use an Online learning Community.

\subsection{Perceived variables}

The next set of variables is grouped around the theme of perceptions. These include PEU, PU and PI. These variables have often been theorised as dominants that affect online learning (Chinyamurindi and Louw, 2010; Chinyamurindi and Shava, 2015; Ong and Lai, 2006). A distinction can be made between these variables. PEU is defined as the degree to which a person believes that using the system would be free of effort (Davis, 1989). Conversely, PU is defined as the degree to which a person believes that using a particular technology would enhance his or her job performance (Davis, 1989). PI is viewed as the interaction that learners experience when using an online community between human-system interaction and interpersonal interaction (Liu et al., 2010). 
According to TAM and empirical findings, a relationship exists between PEU and PU (Chinyamurindi and Louw, 2010; Davis, 1989; Venkatesh and Davis, 2000; Ong and Lai, 2006). The thinking here is that an online learning community perceived by students to be easy to use will be rated to be more useful, thus, resulting in students having stronger intentions to use an online learning community (Liu et al., 2010). In terms of PI, the idea of an online learning community hinges on interaction allowing students to share, recreate and amplify knowledge with others (Nonaka and Nishiguchi, 2001). Such efforts of interaction between students and their lecturers affect the intention to use learning systems such as online learning communities (Liaw, Huang and Chen, 2007). Given this it is expected that

H9: Perceived Ease of Use will positively affect the Perceived Usefulness of an online learning program.

H1O: Perceived Ease of Use will positively affect the Perceived Interaction with an online learning program.

H11: Perceived Usefulness will positively affect the Intention to Use an Online Learning Community.

H12: Perceived Ease of Use will positively affect the Intention to Use an Online Learning Community.

H13: Perceived Interaction will positively affect the Intention to Use an Online Learning Community.

These hypothesised relationships are described graphically in Figure 1.

Figure 1 Research model

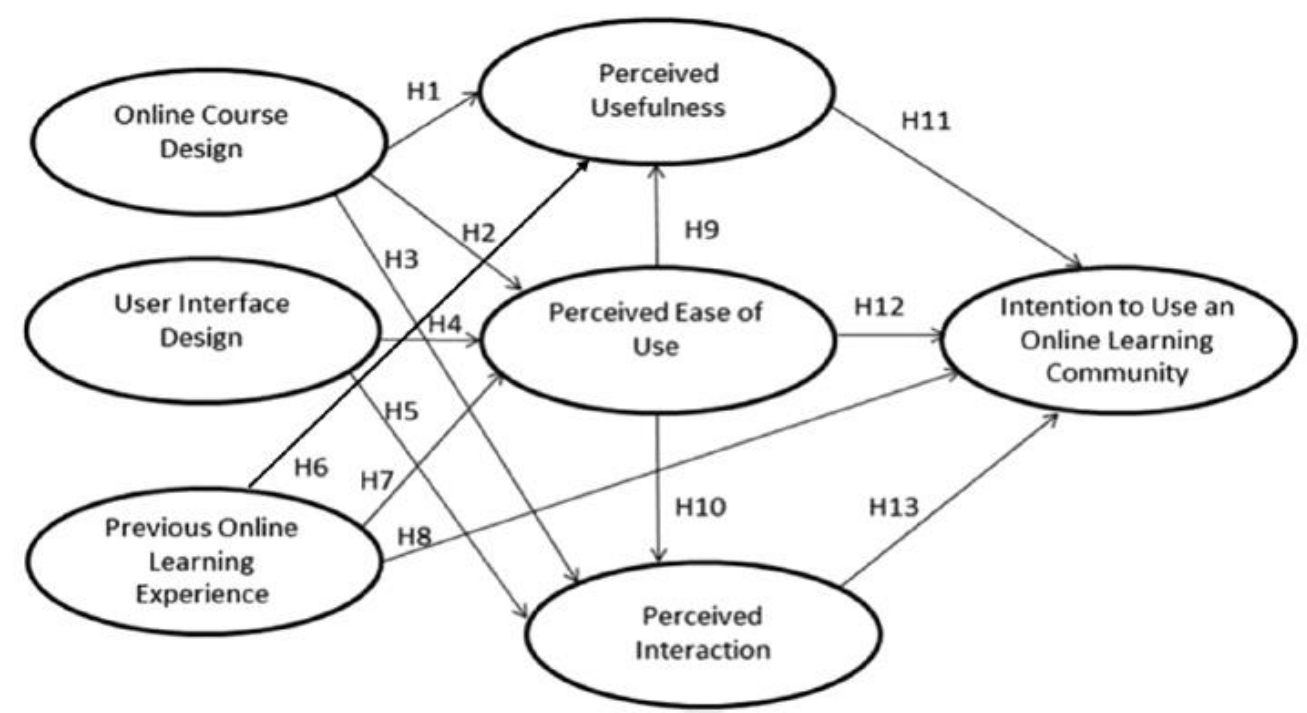




\section{$3 \quad$ Methods \\ 3.1 Research sample}

A total of 300 first year Bachelor of Commerce (B.Com) students took part in the study and from the responses, only 252 students were deemed usable for this research. This yielded a response rate of $84 \%$. A total of 48 responses were not used due to omitted data on the questionnaire. From the usable questionnaires, a total of 111 (44\%) were males and $141(56 \%)$ were females. With regard to age, a total of 89 respondents $(35.3 \%)$ were below the age of 20; a total of 147 respondents (58.3\%) were between the ages 20 and 25; only 10 respondents (40\%) were between the ages of 26 and 30 and finally, a total of six respondents were above the age of $30(2.4 \%)$. The students were also asked to rate their level of computer literacy, and the ratings were as follows: great - 58 participants (23\%); good 127 participants (50.4\%); average - 56 participants (22.2\%) and finally, not so good - 11 participants (4.4\%).

Respondents had been using Blackboard for the duration of the year, a learning management system that allows for collaboration between learners and the lecturer using technology (Schoonenboom, 2014). The platform also offers an opportunity for students to engage with the learning material through using various learning techniques embedded in the Blackboard platform such as Turnitin, Youtube, Sound Cloud, interactive chat, and boards. Thus, Blackboard is also a platform useful for managing the content of a course (Carliner, 2005). Furthermore, the learning approach adopted on the Blackboard platform is rooted in the constructivist approach. This allows students to complete structured exercises with feedback coming from the lecturer and their peers. Lecturers encourage students to use the Blackboard platform from early as the first year so that it prepares them in the subsequent years of their studies. An application for ethical approval was made and granted with the participating higher education institution. Furthermore, before the respondents filled out the questionnaire, they had to give and sign informed consent.

\subsection{Data collection instrument}

All constructs on the questionnaire used to collect data were adapted from established measures. The questionnaire had a total of 27 items and used five-point Likert scale ranging from 'strongly disagree' to 'strongly agree'. Cronbach's alpha coefficient (Cronbach, 1951) was used as a test for internal consistency. The test for reliability using the sample data also showed sufficient reliability of the measure as shown in Table 1. All items except for OCD were above the recommended threshold of 0.70 (Nunnally and Bernstein, 1994). See Appendix A for the instrument. 
Table 1 Reliability analysis of the measure

\begin{tabular}{lcccc}
\hline Scale & $A$ & Total items & Mean & $S D$ \\
\hline Online course design & 0.53 & 4 & 9.46 & 2.18 \\
User interface design & 0.81 & 3 & 6.77 & 2.46 \\
Previous online learning & 0.79 & 4 & 7.33 & 2.62 \\
experience & & & & \\
Perceived usefulness & 0.84 & 4 & 8.81 & 2.83 \\
\hline
\end{tabular}

Table 1 Reliability analysis of the measure (continued)

\begin{tabular}{lcccc}
\hline Scale & $A$ & Total items & Mean & SD \\
\hline Perceived ease of use & 0.75 & 4 & 9.77 & 2.71 \\
Perceived interaction & 0.73 & 4 & 10.58 & 3.39 \\
Intention to use an online & 0.71 & 2 & 4.1 & 1.56 \\
learning community & & & & \\
\hline
\end{tabular}

Note: $\quad \alpha$, Cronbach alpha coefficient

\subsection{Data collection process and data analysis}

Respondents to the study at the end of the 2015 academic year were informed of the study and encouraged to participate by completing an anonymous questionnaire distributed to them during class. All respondents were registered first-year students that had been participating in the Blackboard platform during the year as part of their enrolment. Ethical clearance was applied and granted with the participating institution. Furthermore, before respondents filled out the questionnaire, they gave consent by signing a consent form.

A combination of descriptive and inferential statistics were conducted in the analysis of the data. Item and dimensionality analyses were conducted using the Statistical Package for the Social Sciences (SPSS), Version 22. Structural equation modelling (SEM) was used as a statistical analysis technique using the LISREL 8.80 software. SEM through the use of the LISREL 8.80 allows for the testing of multivariate normality using both the maximum likelihood and robust Maximum likelihood estimation methods via the PRELIS option included in the LISREL 8.80 software. Mahembe and Engelbrecht (2014) argue for SEM as helpful to "explain the patterns of covariances found amongst the observe variables in terms of the relationships" in the hypothesised measurement and structural. Furthermore, the structural model describes relationships between latent variables, and the measurement model describes the relationship between the latent variables and their corresponding indicators (Diamantopoulos and Siguaw, 2000). Finally, in SEM, the implied covariance matrix resulting from the model is then compared with the observed covariance matrix inputted as data to determine model fit (Mahembe and Engelbrecht, 2013). 


\section{Results}

\subsection{Tests of reliability and unidimensionality}

Both item and exploratory factor analyses were performed on the items of the scales used in the study. Based on the SPSS output on the item analysis, item OCD2 of the OCD scale was identified as a poor item with an item total correlation below 0.3 (Pallant, 2010), and its deletion would increase the Cronbach's alpha coefficient from $\alpha=0.529$ to $\alpha=0.624$. The item was, therefore, excluded from further analyses. In general, most of the Cronbach alpha coefficients with the exception of the OCD scale were above the 0.70 threshold (Nunnally and Bernstein, 1994) (see Table 1). Exploratory factor analyses were subsequently performed on the subscales of measures used: unidimensionality was confirmed on all the sub-scales (see Table 2).

Table 2 Descriptive statistics and inter-correlations of the scale scores $(N=252)$

\begin{tabular}{|c|c|c|c|c|c|c|c|c|c|c|}
\hline $\begin{array}{l}\text { Sub- } \\
\text { scales }\end{array}$ & $M$ & $S D$ & 1 & 2 & 3 & 4 & 5 & 6 & 7 & \\
\hline 1 & OCD & 6.89 & 1.95 & 0.62 & & & & & & \\
\hline 2 & UID & 6.77 & 2.46 & $0.13 *$ & 0.81 & & & & & \\
\hline 3 & POE & 7.33 & 2.62 & $0.22 * *$ & 0.07 & 0.79 & & & & \\
\hline 4 & PU & 8.81 & 2.83 & $0.29 * *$ & $0.33 * *$ & 0.11 & .84 & & & \\
\hline 5 & PEU & 9.77 & 2.71 & $0.15^{* * *}$ & $0.33 * *$ & 0.08 & $0.46^{* *}$ & 0.75 & & \\
\hline 6 & PI & 10.58 & 3.39 & $0.22 * *$ & $0.15^{*}$ & $0.22 * *$ & $0.29 * *$ & $0.41^{* *} *$ & 0.73 & \\
\hline 7 & ITU & 4.10 & 1.56 & 0.09 & $0.31 * *$ & $0.14^{*}$ & $0.34^{* *}$ & $0.35^{* *}$ & $0.28^{* * *}$ & 0.71 \\
\hline
\end{tabular}

\subsection{Goodness-of-fit: the measurement models}

In terms of the goodness-of-fit (GFI) indices for the measurement model, the root-meansquare error of approximation (RMSEA) value of 0.034 indicates that the overall measurement model shows a good fit to the data as values below 0.05 represent good model fit. The $p$ value of 0.994 for test of close fit indicates that the model shows close fit to the data (see Table 3). The standardised RMR value of 0.054 marginally missed the 0.05 cut-off indicative of good model fit. The overall measurement model GFI value reached the 0.90 level required to indicate good fit (Diamantopoulos and Siguaw, 2000). The normed fit index (NFI), non-normed fit index (NNFI), comparative fit index (CFI), Incremental Fit Index (IFI) and Relative Fit Index (RFI) are >0.90, which represents good fit (Diamantopoulos and Siguaw, 2000). These relative indices, therefore, demonstrate a positive picture of model fit. 
Table 3 Goodness-of-fit indices obtained for the measurement and structural model

\begin{tabular}{lcccccccc}
\hline & RMSEA & Pclose fit & SRMR & GFI & AGFI & NNFI & NFI & CFI \\
\hline Measurement & 0.034 & 0.994 & 0.054 & 0.90 & 0.86 & 0.98 & 0.92 & 0.98 \\
$\begin{array}{l}\text { Structural } \\
\text { model }\end{array}$ & 0.038 & 0.974 & 0.061 & 0.89 & 0.86 & 0.97 & 0.92 & 0.98 \\
\hline
\end{tabular}

Note: AGFI, adjusted goodness-of-fit index; CFI, comparative fit index; GFI, goodness-of-fit; NFI, normed fit index; NNFI, non-normed fit index; Pclose fit, $p$ value for test of close fit (H0: RMSEA $<0.05)$; RMSEA, root-mean-square error of approximation; SRMR, standardised root-mean residual

\subsection{Measurement model factor loadings}

The completely standardised factor loading for the items contained in the overall measurement model exceeded the $>0.50$ level with the exception of item OCD 1 for the OCD scale which fells marginally below the cut-off level (Hair et al., 2010). This implies that the items generally reflect the dimension that they were designed to represent.

Table 4 The gamma matrix indicating the relationships between exogenous (independent) and endogenous (dependent) variables

\begin{tabular}{lccc}
\hline & $O C D$ & UID & $P O E$ \\
\hline PU & $0.334 \mathrm{a}(0.091)$ & & $-0.052(0.091)$ \\
& $\mathbf{3 . 6 8 ^ { * }}$ & & $-\mathbf{0 . 5 6 7}$ \\
PEU & $0.083(0.096)$ & $0.405(0.102)$ & $0.078(0.091)$ \\
& 0.87 & $\mathbf{3 . 9 8 ^ { * }}$ & $\mathbf{0 . 8 6 2}$ \\
PI & $0.226(0.101)$ & $-0.032(0.103)$ & \\
& $\mathbf{2 . 2 3 ^ { * }}$ & $-\mathbf{0 . 3 1 2}$ & \\
ITU & & & $0.076(0.082)$ \\
& & & $\mathbf{0 . 9 2 2}$ \\
\hline
\end{tabular}

*Significant parameter estimates $t \geq|1.96|$

Note: a, completely standardised path coefficients; standard error estimates

(in brackets); parameter estimates in bold

\subsection{GFI indices for the structural model}

The GFI indices for the structural model generally indicate good model fit. The RMSEA value of 0.038 and $p$ value of 0.974 are good and close model fit to the data (see Table 3). The standardised RMR value of 0.061 missed the 0.05 cut-off level. The structural model GFI (o.89) value marginally missed reached the 0.90 level required to indicate good fit (Diamantopoulos and Siguaw, 2000). The NFI, NNFI, CFI, IFI and RFI indices are >.90, which represents good fit (Diamantopoulos and Siguaw, 2000). 
and H3)

The purpose of evaluating the structural model through SEM is to determine whether the hypothesised theoretical relationships specified at the conceptualisation stage have been confirmed. A positive relationship was found between OCD and PU $(t=3.68, p<0.05)$ (see Table 4). Thus, Hypothesis 1 was confirmed. An insignificant relationship was found between OCD and PEU ( $t=0.87, p>0.05$ ). Consequently, Hypothesis 2 was not supported (see Table 4). The SEM path between OCD and PI was found to be significant, and Hypothesis 3 was supported $(t=2.23, p<0.05)$ (see Table 5 ).

Table 5 The beta matrix indicating the relationships between endogenous (dependent) variables

\begin{tabular}{lcccc}
\hline & $P U$ & $P E U$ & $P I$ & $I T U$ \\
\hline PU & & $0.486 \mathrm{a}(0.088)$ & \\
& & $5.52^{*}$ & \\
PEU & & \\
PI & & & \\
& & & \\
ITU & $0.529(0.124)$ & \\
& $1.98^{*}$ & $0.203(0.130)$ & $0.179(0.120)$ \\
\hline
\end{tabular}

*Significant parameter estimates $t \geq|1.96|$

Note: a, completely standardised path coefficients; standard error estimates (in brackets); parameter estimates in bold

\subsection{Hypotheses testing UID \& PEU/UID and PI (H4 and H5)}

A positive relationship was found between UID and PEU $(t=3.98, p<0.05)$. Consequently, Hypothesis 4 was supported (see Table 4). An insignificant relationship was found between UID and PI $(t=-0.31, p>0.05)$. Consequently, Hypothesis 5 was not supported (see Table 4).

\subsection{Hypotheses testing POL \& PU/POL and ITU (H6, H7 and H8)}

An insignificant relationship was found between POE and PU $(t=-0.57, p>0.05)$. Consequently, Hypothesis 6 was not supported (see Table 4). An insignificant relationship was found between OCD and PEU ( $t=0.86, p>0.05)$. Consequently, Hypothesis 7 was not supported (see Table 4). An insignificant relationship was found between POE and intention to use an online community $(t=0.92, p>0.05)$. Consequently, Hypothesis 8 was not supported (see Table 4).

\subsection{Hypotheses testing OCD and PEU/PEU and PI (H9 and H1O)}

A positive relationship was found between OCD and PEU $(t=5.52, p<0.05)$. Consequently, Hypothesis 9 was supported (see Table 5). A positive relationship was 
found between PEU and PI $(t=4.23, p<0.05)$. Consequently, Hypothesis 10 was supported (see Table 5).

\subsection{Hypotheses testing PU \& ITU (H11), PEU \& ITU (H12) and PI and ITU (H13)}

A positive relationship was found between PU and intention to use an online learning community $(t=1.98, p<0.05)$. Consequently, Hypothesis 11 was supported (see Table 5). Another test found an insignificant relationship was found between PEU and intention to use an online learning community $(t=1.57, p>0.05)$. Consequently, Hypothesis 12 was not supported (see Table 5). Finally, an insignificant relationship was found between PI and intention to use an online learning community ( $t=1.50, p>0.05)$. Consequently, Hypothesis 13 was not supported (see Table 5).

\section{Discussion}

The goal of this research, based on the TAM, was to identify the factors that influence how first-year students at a rural South African university use an online learning community. The variables tested in the study included OCD, UID, POE and PI against behavioural intention to use an online learning community. The research was set within a backdrop of the popularity of ICT within higher education (Mohammadi, 2015), specifically the popularity of online learning communities as part of teaching delivery (Liu et al., 2010). Furthermore, this study worked with first-year students who evaluated an online learning community after using it for a year.

OCD was found to relate with PU of an online learning program. This finding supports previous findings especially within an online learning community (Liu et al., 2010). In essence, students' satisfaction with the online learning curriculum has a bearing on how they evaluate its usefulness. Aspects such as (a) how interesting the online curriculum is, (b) the diversity of approaches adopted in the online curriculum and (c) how the online curriculum fits with the needs of the students lead to a rating of the usefulness of the online learning community. Based on this, a common learning goal (Rovai, 2002) as derived from the online curriculum including consideration of the needs of the students (Dede, 1996) potentially informs not only the perception of the usefulness of the online learning community but also its interaction amongst students. However, OCD was found not to be related with PEU of a learning program. This could be due to issues surrounding the internal consistency of the OCD scale or the entire measuring instrument.

Another salient finding revealed that UID of an online learning community to be related to PEU. The thinking here could be that aspects of usability of an online learning community affect how students use such a system. This confirms previous findings (Liu et al., 2010; McGiven, 1994; Rovai, 2002). In essence, the usability of an online learning community is a robust predictor of student perceptions of ease of use than the PI with such a system (Saadé, Nebebe and Tan, 2007). With regard to a POE, no significant relationship existed between a student's online learning and PU to include also the intention to use an online learning community. In other words, it did not matter if the student had any prior online 
experience with such systems and their intention to use an online learning community. This finding contradicts previous research (Liu et al., 2010).

The study also shows support to the original theorising of the TAM model (Davis, 1986; Venkatesh and Davis, 2000) and support for previous empirical (Agundo- Peregrina, Hernández-García and Pascual-Miguel, 2014; Chinyamurindi and Louw, 2010; Chen, Li and Li, 2011; Saadé, Nebebe and Tan, 2007) concerning PU and intention to use an online learning community. Ideally, it means that an easy to use system is perceived by users to be more useful and favouring the intention to use an online learning community (Liu et al., 2010).

\subsection{Theoretical and practical implications}

Some implications can be drawn from this research. First, the study places the importance of UID on the experience and intention of using an online learning program. Close attention needs to be given how online learning communities are designed as this relates not only how they are used but also perceptions of their usefulness. Not only can this have a bearing on student confidence in using such systems but also on the continual navigation of such systems (Venkatesh and Davis, 2000). Paying attention to such a factor can be helpful in improving teaching practice from the lecturer's point of view while benefiting the student.

Second, related to the first implication, there is a need for continual support for both students and lecturers when using online learning communities. Such capacity building efforts should also be informed through institutional support mechanisms. Although there is an acknowledgement that first-year students, especially from disadvantaged backgrounds face challenges in their enrolment at tertiary institutions (Zulu, 2011), in some cases (as with POE), this has no bearing in their current and future enrolment. In essence, it is what is done in the present (not necessarily what happened in the past) that sets the agenda for either a positive or negative online learning experience. Hence, the argument that building capacity in the present is important. Third, this study extends understanding around technology utilisation including its utility and applicability especially within an educational setting (Hsiao and Yang, 2011; Park, 2009).

Finally, by paying attention to the factors in the hypothesised model (Figure 1), lecturers may overcome barriers that affect technology adoption and utilisation. Paying attention to such factors has a bearing on the optimal and efficient use of technology amongst the student cohort. The findings of this study have informed teaching practice and have allowed the researchers to come up with practical interventions to help students with technology adoption. The researchers have started offering tutorials and personalised assistance for students addressing aspects of the TAM constructs, thus, creating a student-friendly online learning community. The thinking here was that the factors in the hypothesised model (Figure 1) and also informed by the TAM can help identify how to improve teaching within higher education using ICT. 
Based on these findings, assistance was also asked from the teaching and learning centre to offer courses that address basic issues such as computer appreciation skills and how to help students manage their learning using technology. Furthermore, one of the authors of this paper went on a web-based learning course to help develop capacity in as far as designing and using technology within learning systems. To this end, this study was a useful window in revealing not only factors influencing online learning communities amongst first-year students but also a basis for suggesting practical interventions while also contributing theoretically.

\subsection{Limitations and an agendafor future research}

Some limitations exist with this work. First, the sample is not generalisable to the entire population of students using technology within a higher education setting. Some factors relating to this can be due to the nature of the institution which attracts predominantly Black students. Notably, other race groups found in South African society are not found in the sample, owing to the demographics at the institution. This skewed sample seriously comprises the study and limits its generalisability. Second, although the TAM is viewed as a robust predictor of intention (Saadé, Nebebe and Tan, 2007), other theoretical frameworks and variables could have been used to add to the predictive power of the TAM. For instance, there is work advocating for the extended TAM (Cheung and Vogel, 2013), incorporating factors such as compatibility, perceived resources and sharing. Finally, there are concerns with the levels of internal consistency with the instrument used. These concerns point to issues of validity and item construction. Although these are limitations for this study, they can also represent an opportunity for future research.

Future research could also be in the form of a longitudinal study with the same sample of students used over their undergraduate enrolment and their usage of technology in teaching. Future research can also address issues around the validity and item construction concerning the instrument cited as limitations of this research. This can in the form of empirical testing such as the validation of the instrument used across different settings. Such a study can be useful in tightening on items in the instruments. Finally, a qualitative angle on the student experience of online learning communities can prove helpful and shed further insight to some of the findings of this work. This can be an agenda for future research, not a final word but an agenda for continued sense making concerning the use of technology within teaching instruction. 


\section{References}

Agundo-Peregrina, Á.F., Hernández-García, Á. and Pascual-Miguel, F.J. (2014) 'Behavioral intention, use behavior and the acceptance of electronic learning systems: differences between higher education and lifelong learning', Computers in Human Behavior, Vol. 34, pp.301-314.

Carliner, S. (2005) 'Integrating the web into education for technical communication majors: a process-oriented approach', in Day, M. and Lipson, C. (Eds.): Technical Communications and the World Wide Web, Lawrence Erlbaum Associates, Mahwah, NJ.

Chen, S.H., Li, S.H. and Li, C.Y. (2011) 'Recent related research in technology acceptance model: a literature review', Australian Journal of Business and Management Research, Vol. 1, No. 9, pp.124-127.

Chinyamurindi, W.T. and Louw, G.J. (2010) 'Gender differences in technology acceptance in selected South African companies: implications for electronic learning', South African Journal of Human Resource Management, Vol. 8, No. 1, pp.1-7.

Chinyamurindi, W. and Shava, H. (2015) 'An investigation into e-learning acceptance and gender amongst a sample of final year students', South African Journal of Information Management, Vol. 17, No. 1, pp.1-9.

Cheung, R. and Vogel, D. (2013) 'Predicting user acceptance of collaborative technologies: an extension of the technology acceptance model', Computers \& Education, Vol. 63, pp.160-175.

Compeau, D.R. and Higgins, C.A. (1995) 'Computer self-efficacy: development of a measure and initial test', MIS Quarterly, Vol. 19, No. 2, pp.189-211.

Cronbach, L.J. (1951) 'Coefficient alpha and the internal structure of tests', Psychometrika, Vol. 22, No. 3, pp.297-334.

Czerniewicz, L. and Brown, C. (2014) 'The habitus and technological practices of rural students: a case study', South African Journal of Education, Vol. 34, No. 1, pp.1-14.

Davis, F. (1989) 'Perceived usefulness, perceived ease of use, and user acceptance of information technology', MIS Quarterly, Vol. 13, No. 3, pp.318-339.

Dede, C. (1996) 'The evolution of distance education: emerging technologie and distributed learning', American Journal of Distance Education, Vol. 10, No. 2, pp.436.

Diamantopoulos, A. and Siguaw, J.A. (2000) Introducing LISREL, Sage Publications, London, UK.

Fink, L.D. (2003). Creating Significant Learning Experiences: An Integrated Approach to Design College Courses, Jossey-Bass, San Francisco, CA.

Foreman, S.K. (1999) 'Marketing: marketing organization and virtual communities', Manager Update, Vol. 11, No, 1, pp.11-21.

Hair, J.F., Black, W.C., Babin, B.J., Anderson, R.E. and Tatham, R.L. (2006) Multivariate Data Analysis, Pearson Prentice, Upper Saddle River, NJ.

Hramiak, A. (2010) 'Online learning community development with teachers as a means of enhancing initial teacher training', Technology, Pedagogy and Education, Vol. 19, No, 1, pp.47-62. 
Hsiao, C.H. and Yang, C. (2011) 'The intellectual development of the technology acceptance model: a co-citation analysis', International Journal of Information Management, Vol. 31, No. 2, pp.128-136.

Ilechukwu, L.C. (2013) 'The assessment of utilization of e-learning opportunities for effective teaching and learning of religion in Nigerian tertiary institutions', European Journal of Educational Studies, Vol. 5, No. 3, pp.343-359.

Lee, D.Y. and Lehto, M.R. (2013) 'User acceptance of YouTube for procedural learning: an extension of the technology acceptance model', Computers and Education, Vol. 61, pp.193-208.

Leflore, D. (2000) Theory Supporting Design Guidelines for Web-Based Instruction. Instructional and Cognitive Impacts of Web-Based Education. Idea Group Publishing, Hershey, PA.

Liaw, S.S., Huang, H.M. and Chen, G.D. (2007) 'An activity-theoretical approach to investigate learners' factors toward e-learning systems', Computers in Human Behavior, Vol. 23, pp.1906-1920.

Liu, I.F., Chen, M.C. and Sun, Y. (2006) 'The design of a web-based learning platform: a case study in Taiwan', Proc. 14th Int. Conf. Comput. Edu. (ICCE2Oo6), Beijing, China.

Liu, I.F., Chen, M.C., Sun, Y.S., Wible, D. and Kuo, C.H. (2010) 'Extending the TAM model to explore the factors that affect intention to use an online learning community', Computers \& Education, Vol. 54, pp.600-610.

Mahembe, B. and Engelbrecht, A.S. (2013) 'The relationship between servant leadership, affective team commitment and team effectiveness', South African Journal of Human Resource Management, Vol. 11, No. 1, pp.1-10.

Mahembe, B. and Engelbrecht, A.S. (2014) 'The relationship between servant leadership, organisational citizenship behaviour and team effectiveness', South African Journal of Industrial Psychology, Vol. 40, No. 1, pp.1-10.

Martin-Michiellot, S. and Mendelsohn, P. (2000) 'Cognitive load while learning with a graphical computer interface', Journal of Computer Assisted Learning, Vol. 16, No. 4, pp.284-293.

McGiven, J. (1994) 'Designing the learning environment to meet the needs of distant students', Journal of Technology and Learning, Vol. 27, No. 2, pp.52-57.

McKnight, C., Dillon, A. and Richardson, J. (1996) 'User centred design of hypertext and hypermedia for education', in Jonassen, D. (Ed.): Handbook of Research on Educational Communications and Technology, Macmillan, New York, pp.622-633.

McNeil, S.G., Robin, B.R. and Miller, R.M. (2000) 'Facilitating interaction, communication and collaboration in online courses', Computers and Geosciences, Vol. 26, pp.699708.

Mohammadi, H. (2015) 'Investigating users' perspectives on e-learning: an integration of TAM and IS success mode', Computers in Human Behavior, Vol. 45, pp.359-374.

Nonaka, I. and Nishiguchi, T. (2001) Knowledge Emergence, Social, Technical, and Evolutionary Dimensions of Knowledge Creation, Oxford University Press, Oxford.

Nunnally, J.C. and Bernstein, I.H. (1994) Psychometric Theory, McGraw-Hill, New York, NY. 
Ong, C.S. and Lai, J.Y. (2006) 'Gender differences in perceptions and relationships among dominants of e-learning acceptance', Computers in Human Behaviour, Vol. 22, No. 5, pp.816-829.

Pallant, J. (2010) SPSS Survival Manual: A Step by Step Guide to Data Analysis Using SPSS, McGraw-Hill, Maidenhead, UK.

Park, S.Y. (2009) 'An analysis of the technology acceptance model in understanding university students' behavioural intention to use e-learning', Educational Technology and Society, Vol. 12, No. 3, pp.150-162.

Ramage, M. (2010) 'Evaluating collaborative technologies: a simple method', in Donelan, H., Kear, K. and Ramage, M. (Eds.): Online Communication and Collaboration: A Reader, Routledge, London and New York, pp.73-77.

Reed, W.M. and Geissler, S.F. (1995) 'Prior computer-related experience and hypermedia metacognition', Computers in Human Behavior, Vol. 11, No. 3, pp.581-60o.

Rovai, A.P. (2002) 'Sense of community, perceived cognitive learning, and persistence in asynchronous learning networks', Internet and Higher Education, Vol. 5, pp.312-319.

Saadé, R. and Bahli, B. (2005) 'The impact of cognitive absorption on perceived usefulness and perceived ease of use in on-line learning: an extension of the technology acceptance model', Information and Management, Vol. 42, pp.317-327.

Saadé, R.G., Nebebe, F. and Tan, W. (2007) 'Viability of the technology acceptance model in multimedia learning environments: a comparative study. Interdisciplinary', Journal of Knowledge and Learning Objects, Vol. 3, No. 1, pp.175-184.

Schoonenboom, J. (2014) 'Using an adapted, task-level technology acceptance model to explain why instructors in higher education intend to use some learning management system tools more than others', Computers \& Education, Vol. 71, pp.247-256.

Shih, P.C., Muroz, D. and Sanchez, F. (2006) 'The effect of previous experience with information and communication technologies on performance in a web-based learning program', Computers in Human Behavior, Vol. 22, No. 6, pp.962-970.

Sun, H. and Zhang, P. (2006) 'The role of moderating factors in user technology acceptance', International Journal of Human Computer Studies, Vol. 64, pp.53-78.

Venkatesh, V. and Davis, F.D. (2000) 'A theoretical extension of the technology acceptance model: four longitudinal field studies', Management Science, Vol. 46, No. 2, pp.186204.

Wang, S.K. and Yang, C. (2005) 'The interface design and the usability testing of a fossilization web-based learning environment', Journal of Science Education and Technology, Vol. 14, No. 3, pp.305-313.

Yuan, Y.M., Raubal, M. and Liu, Y. (2012) 'Correlating mobile phone usage and travel behavior: a case study of Harbin, China', Computers, Environment and Urban Systems, Vol. 36, No. 2, pp.118-130.

Zulu, C. (2005) 'Academic reading ability of first-year students: what's high school performance or prior exposure to academic reading got to do with it', Southern African Linguistics and Applied Language Studies, Vol. 23, pp.111-123.

Zulu, C. (2007) 'First-year university L2 readers' patterns of performance in a test of academic reading ability', Language Matters, Vol. 38, pp.316-331. 
Zulu, C. (2008) 'An exploratory study of first-year students at a historically black university campus in South Africa: their academic experiences, success and failure', Africa Education Review, Vol. 5, pp.30-47.

Zulu, C. (2011) 'Empowering first year (post-matric) students in basic research skills: a strategy for education for social justice', South African Journal of Education, Vol. 31, No. 3, pp.447-457. 


Item statement reference

Online course design (OCD)

Source

OCD1. The course content is interesting

OCD2. The course content level is mid-range

OCD3. The course content meets my needs

OCD4. In general, I am satisfied with the design of the course content and quality

\section{User interface design (UID)}

Liu et al. (2010)

UID1. The layout design of the website makes it easy to read

UID2. The font style, colour and layout of the interface make it comfortable for me to read

UID3. In general, I am satisfied with the design of the interface of this website

\section{Previous online learning experience (POL)}

Liu et al. (2010)

POL1. I feel it would easier to operate the system if I had previous experience of using it

POL2. I will have a better understanding of how to use the system if it has a function for online guidance

POL3. I will have a better understanding of how to use the system if a teacher or peer operates it first

\section{Perceived usefulness (PU)}

Davis $(1989,1993)$,

PU1. I could improve my learning performance by using this system

PU2. I could enhance my language learning proficiency by using this system

PU3. I could increase my learning productivity by using this system

PU4. I think using this system helps me learn

Perceived ease of use (PEU)

Davis $(1989,1993)$,

PEU1. This system makes people feel that the interface design and information delivery Venkatesh and Davis (1996) are clear and easy to understand

PEU2. It is easy for me to do the things that I want to do by operating this system

PEU3. I feel this system is easy to handle when I encounter a problem

PEU4. In general, I feel it is easy for me to use this system 
Appendix A. Measurement items used in this study (continued)

\begin{tabular}{lc}
\hline Item statement reference & Source \\
\hline Perceived interaction (PI) & Liu et al. (2010) \\
PI1. I discuss relevant English learning topics with others on the & \\
discussion board & \\
PI2. I send e-mails to others as a way of communicating & \\
PI3. I engage in simultaneous learning interaction with others via & \\
Instant Messenger & \\
PI4. In general, I think this web-based learning environment provides & \\
good opportunities for interaction with other users & Davis (1989, 1993), \\
Intention to use an online learning community (ITU) & Venkatesh (2001) \\
ITU1. I intend to use this system for activities that involve my & \\
learning & \\
ITU2. I will reuse this system for relevant learning activities & \\
\hline
\end{tabular}

